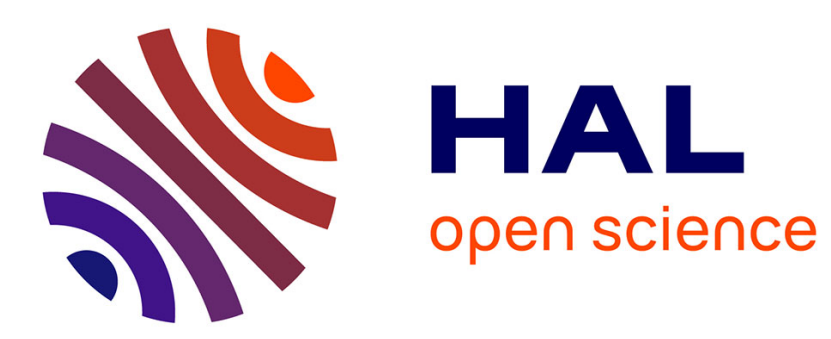

\title{
An investigation of in-plane dynamic behavior of adhesively-bonded composite joints under dynamic compression at high strain rate
}

\author{
Sonia Sassi, Mostapha Tarfaoui, Hamza Ben Yahia
}

\section{- To cite this version:}

Sonia Sassi, Mostapha Tarfaoui, Hamza Ben Yahia. An investigation of in-plane dynamic behavior of adhesively-bonded composite joints under dynamic compression at high strain rate. Composite Structures, 2018, 191, pp.168 - 179. 10.1016/j.compstruct.2018.02.057 . hal-01727700

\section{HAL Id: hal-01727700 \\ https://hal-ensta-bretagne.archives-ouvertes.fr/hal-01727700}

Submitted on 13 Mar 2019

HAL is a multi-disciplinary open access archive for the deposit and dissemination of scientific research documents, whether they are published or not. The documents may come from teaching and research institutions in France or abroad, or from public or private research centers.
L'archive ouverte pluridisciplinaire HAL, est destinée au dépôt et à la diffusion de documents scientifiques de niveau recherche, publiés ou non, émanant des établissements d'enseignement et de recherche français ou étrangers, des laboratoires publics ou privés. 


\title{
An investigation of in-plane dynamic behavior of adhesively-bonded composite joints under dynamic compression at high strain rate
}

\author{
Sonia Sassi*, Mostapha Tarfaoui, Hamza Ben Yahia \\ ENSTA Bretagne, FRE CNRS 3744, IRDL, F-29200 Brest, France
}

\begin{abstract}
This study examines the behaviour of adhesively-bonded composite joints under dynamic compression tests. The purpose of this work is to use the split Hopkinson pressure bar (SHPB) for the dynamic characterization of adhesively bonded joints subjected to in-plane compression loading and in particular, the effect of strain rate on the mechanical behaviour and the damage kinetics. These joints are studied using glass/vinylester composite materials which are frequently used in naval applications Compression tests are performed at different strain rates using SHPB and high speed camera has been used to follow the damage progression. The experimental results have shown that the dynamic properties change with respect to the change in strain rate. Fibre buckling and delamination are the main damage criterias seen in the specimens under in-plane compressive tests. Therefore, this study not only allows us to understand the dynamic response of the adhesively bonded joints under dynamic compression but also enables us to establish damage models based on strain rate effect, for structure design purposes.
\end{abstract}

\section{Introduction}

As the role of structural adhesives becomes more pronounced in composites used in technological applications such as aeronautics, military and naval etc, it has become necessary to understand the dynamic behavior of adhesively bonded joints. To design structures subjected to high impact loads in such applications, the knowledge of dynamic properties is required for developing constitutive models of the tested materials $[1,2]$. In addition, the link between the dynamic behavior and the dynamic damage evolution in adhesively bonded joints at high strain rates, is still far from being fully understood. Thus, it is significant to achieve an accurate description of damage under dynamic loading and effect of strain rate on the behavior of these materials for safety and design considerations. The split Hopkinson bar (SHPB) has been widely used to determine the dynamic properties of materials at high strain rates [3-12]. Significant efforts have been made to investigate the effect of high strain rate on the dynamic behaviour of polymers adhesives and composites laminates using the Split Hopkinson bar under various loading conditions [13-16]. Hosur et al. [17] investigated the dynamic response of unidirectional carbon/epoxy composite material subjected to in-plane dynamic compression tests using SHPB with different strain rates of 82,164 and $817 \mathrm{~s}^{-1}$. They compared the dynamic results with static compression tests and observed that strength and stiffness of the material are higher in dynamic compression than in static compression test. Kumar et al. [13] studied the dynamic compressive response of unidirectional glass/epoxy composite at various off-axis angles in the transverse and logitidunal direction.

They demonstrated in their study that the longitudinal compressive strength and failure strain increase however, the longitudinal modulus decreases with increasing strain rate. El-Habak et al. [14] examined the mechanical behaviour of woven glass fibre-reinforced composites at strain rates from $10^{2}$ to $10^{3} \mathrm{~s}^{-1}$ for three types of matrix (polyester, vinylester and epoxy). They concluded that the vinyester matrix allows to obtain the highest strength. Tarfaoui et al. [5] studied the strain rate effect on the dynamic behaviour of glass fibre reinforced polymer under in-plane and out-of-plane dynamic compression tests using SHPB varying the fibres orientation and the loading conditions. The results showed that the dynamic strength of the material depends strongly on fibre orientation and impact pressure for in-plane tests and the material is significantly sensitive to fibre orientation for out-of-plane tests at the same impact pressure. Arbaoui et al. $[9,10]$ studied the dynamic compressive behaviour of $\left[0 / 90^{\circ}\right]_{26}$ glass/epoxy laminates in-plane and outof-plane directions using (SHPB). They concluded that the dynamic properties are strain rate sensitive and the material is more resistant in the case of out-of-plane loading as compared to the in-plane loading case. Li et al. [18] studied the thermodynamic behaviour of unidirectional carbon/epoxy laminate subjected to in-plane and out-plane

\footnotetext{
* Corresponding author.

E-mail addresses: sonia.sassi@ensta-bretagne.fr (S. Sassi), mostapha.tarfaoui@ensta-bretagne.fr (M. Tarfaoui).
} 
dynamic compression and tensile tests at different strain rates using (SHPB). It was concluded that the damage modes are responsible for heat dissipation in the material for both dynamic tests.

It is apparent from the available literature that little research has been carried out to study the dynamic behaviour of the adhesively bonded joints in comparison with the specimens made entirely in polymeric adhesives [19-24]. Although, obtaining reliable data regarding these adhesively bonded joints is complex and depends upon the combination of different materials but in general, most of the research is carried out to investigate either the adhesive formulation, or to study the effect of the strain rate and temperature on adhesive under dynamic impact using various simple ad hoc tests. For example, L. Goglio et al. [20] studied the effect of the strain rate on the dynamic tensile and compression strength of specimens made of adhesive «epoxy» using the SHPB. Their results showed that the adhesive strength increases substantially by increasing the strain-rate. Takeshi Iwamoto et al. [21] investigated the effect of strain rate on the compressive stress-strain behaviour of epoxy resin adhesive using SHPB. They concluded that in the elastic deformation, a semi-logarithmic approach could be established to link the peak stress in the low strain rate and nonlinear laws in high strain rates. To explained the non-linear behaviour, the authors have defined rheological models taking into account the plastic deformation of the glassy epoxy polymer. Sharon et al. [24] studied the effects of loading rate and temperature on the mechanical properties of four structural adhesives. They demonstrated that the yield stress and modulus decreased with temperature, while increase in loading rate resulted in an increase in yield stress with negligible influence on the modulus. Calberger et al. [19] studied the effect of the temperature and the strain rate on the cohesive properties of an epoxy adhesive. Their results showed a negligible effect of temperature on the fracture thoroughness from $-40^{\circ} \mathrm{C}$ to $80^{\circ} \mathrm{C}$ (the glass transition temperature of the epoxy adhesive investigated is $+90^{\circ} \mathrm{C}$ ) but the peak stress in peel loading decreased significantly with increasing temperature in this range and both cohesive parameters increased with increasing the strain rate. Srivastava et al. [25] investigated the effects of temperature and strain rate on the bond strength of lap joints in Ti-6Al-4 V and C/C-SiC composite. They concluded that the bond strength decreases by $40-50 \%$ at $300{ }^{\circ} \mathrm{C}$, while it increases with the strain rate. So, it is clear that adhesive materials are high strain rate sensitive. Therefore, it can be expected that the dynamic response of adhesive joints would be strongly dependent on the strain rate under impact conditions.

In this study the effect of the strain rate on the dynamic behaviour of adhesively-bonded composite joints subjected to in-plane loading using SHPB is investigated. Compression tests were performed at four different impact pressures (1, 2, 3 and 4 bar). High speed camera was used to draw up the history of the dynamic damage in the specimens in response to the strain rate evolution. The failure modes of adhesivelybonded composite joints have been determined and also discussed. To summarize the experimental results, empirical models depending upon the strain rate effect, have been established. These empirical models will play a useful role in developing damage models for design optimization of adhesively-bonded composite structures.

\section{Experimental procedure}

\subsection{Materials}

The material used in this study is the one taken directly from a real superstructure of Fregate. It consists of a $45^{\circ} \mathrm{Bi}$-axial fiber-glass mat of $0.286 \mathrm{~mm}$ thickness in a Polyester resin matrix. In adhesive bonding, a NORPOL Polyvinylester of $1 \mathrm{~mm}$ thickness has been used to assemble the composite substrate. The composite mechanical properties are given in Tables 1-3. For these dynamic compression tests, samples with $13 \mathrm{~mm} \times 13 \mathrm{~mm} \times 9 \mathrm{~mm}$ for in-plane tests are considered, as illustrated in Fig. 1. Before conducting the in-plane dynamic tests on the
Table 1

Physical properties of the fiber glass mat.

\begin{tabular}{lllll}
\hline Construction & $\begin{array}{l}\text { Areal weight } \\
\left(\mathrm{g} / \mathrm{m}^{2}\right)\end{array}$ & Tolerance $( \pm \%)$ & Material & $\begin{array}{l}\text { Linear } \\
\text { density (tex) }\end{array}$ \\
\hline$+45^{\circ}$ & 451 & 5 & E-Glass & 600 \\
$-45^{\circ}$ & 451 & 5 & E-Glass & 600 \\
Stitching & 12 & 5 & PES 76 dtex & \\
Total area & 912 & 5 & Binder & Warp \\
$\quad$ weight & & & & \\
\hline
\end{tabular}

Table 2

Mechanical properties of orthotropic layer (glass/vinylester).

\begin{tabular}{ll}
\hline Properties & Values \\
\hline Density $\left(\mathrm{kg} / \mathrm{m}^{3}\right)$ & 1960 \\
Young's modulus (MPa) & $E_{1}=48110, E_{2}=E_{3}=11210$ \\
Poisson's ratio & $\nu_{12}=\nu_{13}=0.28, v_{23}=0.34$ \\
Shear modulus (MPa) & $G_{12}=G_{13}=4420, G_{23}=5000$ \\
Longitudinal Tensile strength (MPa) & $X_{t}=965.50$ \\
Longitudinal compressive strength (MPa) & $X_{c}=900$ \\
Transversal tensile strength (MPa) & $Y_{t}=Z_{t}=33.50$ \\
Transversal compressive strength (MPa) & $Y_{c}=Z_{c}=134$ \\
Shear strength (MPa) & $S_{12}=S_{13}=S_{23}=48.69$ \\
\hline
\end{tabular}

Table 3

Mechanical properties of adhesive.

\begin{tabular}{ll}
\hline Properties & Values \\
\hline Density $\left(\mathrm{kg} / \mathrm{m}^{3}\right)$ & 1960 \\
Young's modulus (MPa) & $\begin{array}{l}\mathrm{E}=3100 \\
\nu=0.3\end{array}$ \\
Poisson's ratio & 51.25 \\
Strength to final failure (MPa) & \\
\hline
\end{tabular}

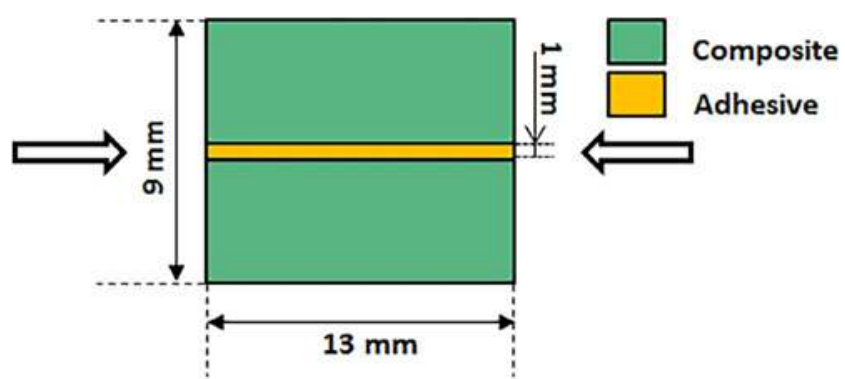

Fig. 1. Adhesively-bonded composite joints specimen subjected to in-plane loading.

Hopkinson bars, it is necessary to ensure that these tests can be reproduced. With this objective in mind, a minimum of three tests were carried out at the same impact pressure in order to analyse tests reproducibility.

\subsection{SHPB method}

In this study, the in-plane dynamic compressive loading is ensured using the SHPB apparatus (Fig. 2). Details of the SHPB experimental protocol are mentioned in [3-12].The SHPB apparatus basically consists of an incident bar, a transmitted bar and sticker bar. Both the incident and transmitted bars have a diameter of $20 \mathrm{~mm}$ and a length of $1.9850 \mathrm{~m}$. A striker bar of $20 \mathrm{~mm}$ diameter and a length of $2 \mathrm{~m}$ is used to generate an incident stress via impact with the incident bar. Specimens of adhesively bonded assemblies are placed between the incident and transmitted bars without any attachment to prevent perturbations of measurements due to additional interfaces [26]. To vary the strain rates under different compressive tests, the striker velocity is adjusted by varying the pressure to achieve a range of incident load magnitudes. 


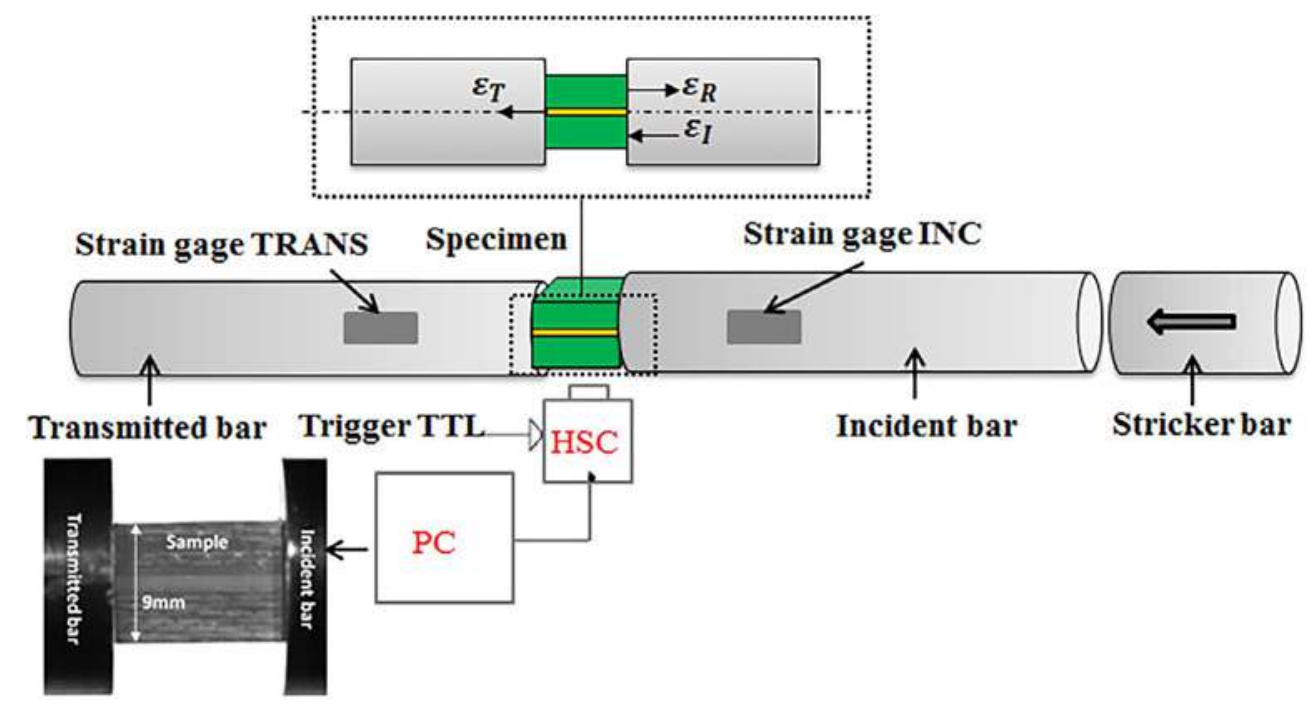

Fig. 2. Split Hopkinson bar apparatus.

This induces the generation of one dimensional compressive stress by the axial impact between the striker and the incident bar. The duration of this wave is dependent on the length of the striker. Once reaching the incident interface between the specimen and the incident bar, a portion of the compressive wave is reflected back along the incident bar, while the rest is transmitted to the transmitted bar. Two strain gages are bonded longitudinally along each pressure bar to measure the incident, $\varepsilon_{I}$, reflected, $\varepsilon_{R}$, and transmitted, $\varepsilon_{T}$, signals. These signals are recorded on an oscilloscope and digitized subsequently with Maple Software algorithm using Fast Fourier Transformation to obtain the dynamic parameters: stress vs. strain, strain rate vs. time, incident and transmitted load and velocity vs. time at the interfaces incident of bar/ specimen and transmitted bar/specimen.

During the dynamic compression tests, high speed camera (HSC) was used to follow in situ and in real time the damage scenario in the specimen. This camera was set to a framing rate of 50,000 images per second and is activated just prior to launching of the striker.

\section{Experimental results}

\subsection{Strain rate dependencies of mechanical properties}

Fig. 3 shows typical signals for the above mentioned dynamic compressive tests at 1 bar and 4 bar. The incident and transmitted waves are compressive while the reflected wave is tensile. It can be seen that the respective incident, reflected and transmitted wave heights depend significantly on the striker bar velocity. As expected [3-12], the second peak of the reflected pulse and the short duration of the transmitted pulse, show the presence of macroscopic damage in the adhesively bonded joints when it is subjected to the in-plane compressive loads. Thus, it can be concluded that the tests at 1 bar correspond to the non damaged case during which the pressure wave is reflected back through the assembled specimen with a fairly elastic response. The input signals are converted to the loads, velocities (at both ends of the specimen) and to the average stress of the specimen under dynamic compressive tests. Fig. $3 \mathrm{c}-\mathrm{h}$ show the loads vs. time, velocities vs. time and stress-strain curves for non damaged and damaged tests. Concerning the loads and the velocities curves, it has been firstly shown that these curves at both ends of the specimen were equilibrated which satisfies the basic assumption for a valid SHPB experiment. Secondly, both the incident loads and velocity profiles simultaneously show the appearance of the second peak which signifies the presence of macroscopic damage in the case of damaged test.

Before performing the dynamic compression tests, it is necessary to ensure reproducibility of the tests. To address this issue, a minimum of three tests was carried out to analyze dispersion for each impact pressure. It can be seen in Figs. 4-6 that dispersion is weak and that and it was for all the tests and at each impact pressure.

Clearly, the strain rate response is sensitive to the entry pressure $\mathrm{P}$ in the chamber of compressed air (Fig. 4). In the first step, the strain rate increases rapidly under reaching a maximum value which is proportionally depended to the impact pressure. Then, it decreases and subsequently tends to go down to zero for the impact pressure 1 and 2 bar. For these impact pressures, the fall of strain rate reaches negative values, which correspond to the springback in the sample. However, the increase in impact pressure ( 3 and 4 bar) shows that the strain rate increases before the decrease in the second step. The appearance of a second peak is the principal characteristic of these curves detecting the presence of the onset of macroscopic damage as demonstrated by Tarfaoui et al. [3-12].

To simplify the graphic representations, it is proposed to compare the evolutions of stress vs. strain, incident and transmitted loads vs. time, incident and transmitted velocities vs. time curves of non damaged and damaged in-plane dynamic compression tests.

Fig. 5 shows the stress-strain behaviors for strain rate at $210 \mathrm{~s}^{-1}$ and $713 \mathrm{~s}^{-1}$ corresponding to impact pressures of 1 bar and 4 bar, respectively. Clearly, the dynamic compressive behavior of the adhesively bonded joints is strongly affected by the strain rate. The stress-strain tendency in each case was similar during the linear elastic response, without any damage at small strain. For non damaged tests, one can note that the assembled samples tend to return to their original state, with nearly zero plastic deformation. However for the damaged tests, the elastic linear behavior is followed by the appearance of the first peak which corresponds to the initiation of the microscopic damage modes as matrix cracks. The presence of the second peak can be attributed to the delamination in the assembled sample. After reaching the ultimate stress, one can observe more dynamic oscillations in the non linear part which correspond to the propagation of the damage and its accumulation with increasing strain on a macroscopic scale.

Fig. 6 shows typical signals time variations of incident and transmitted loads and velocities for non damaged and damaged tests. It can be noted that assumptions of equilibrium are reasonable as the incident and the transmitted loads are rather similar for non damaged and damaged strain rates. However, for each strain rate, a small difference between the incident and the transmitted loads is marked. This can not only be attributed to the self-installation of the assembled sample between the bars but also to the parallelism of the samples facets in contact with the bars which is not $100 \%$ guaranteed, as shown in 

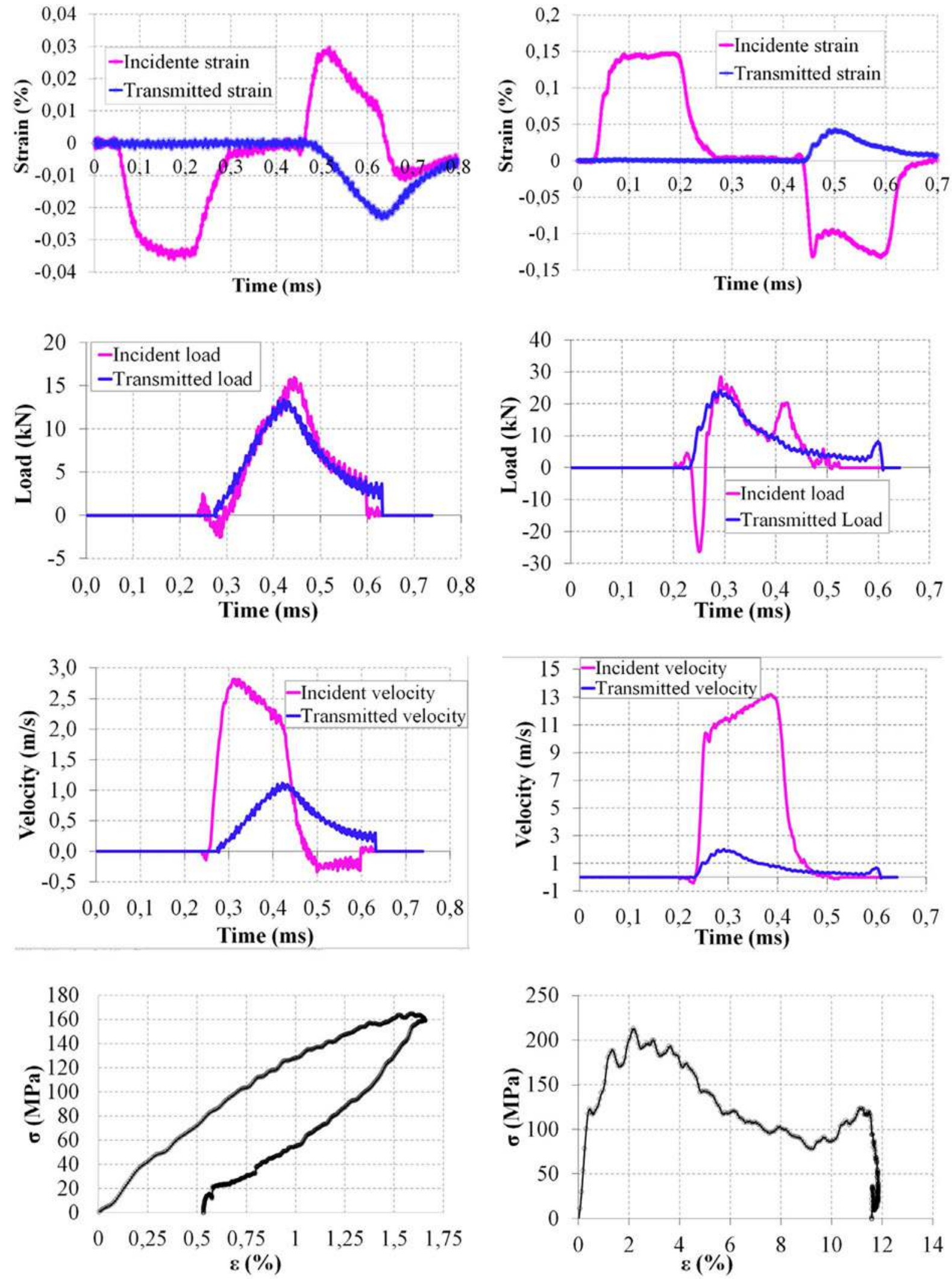

(a) Non damaging test $(P=1$ bar $)$

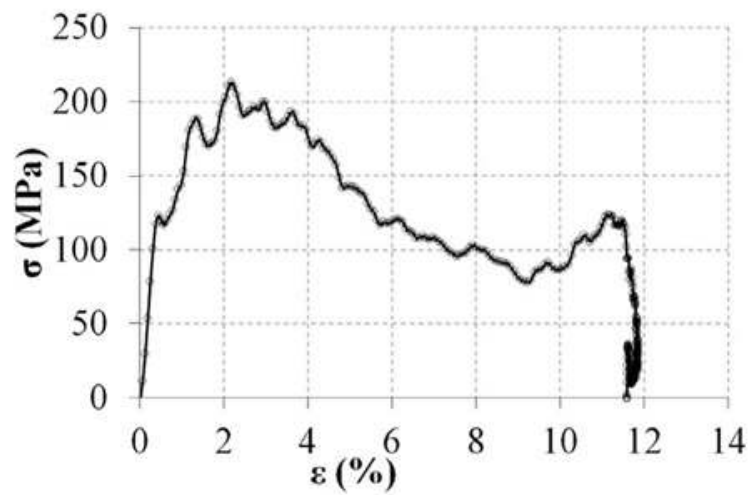

(b) Damaging test $(P=4$ bar $)$

Fig. 3. Typical results of signal processing from gauges. 


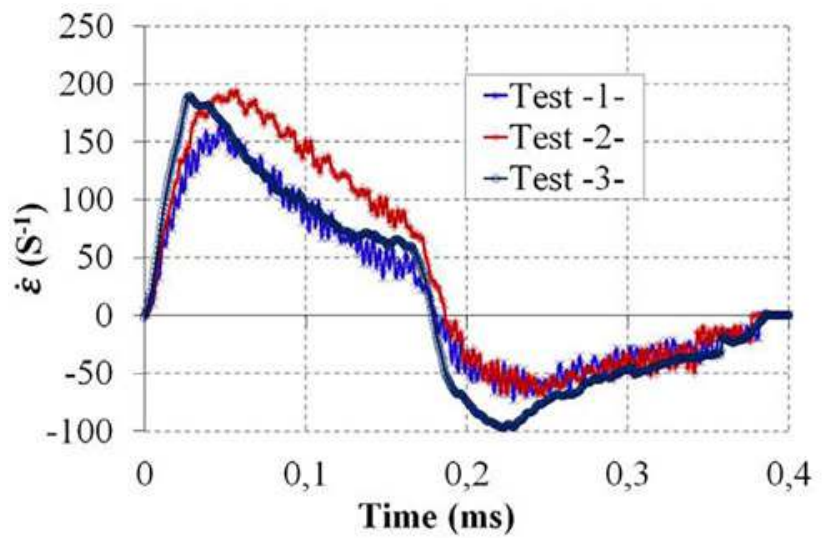

(a) 1 bar

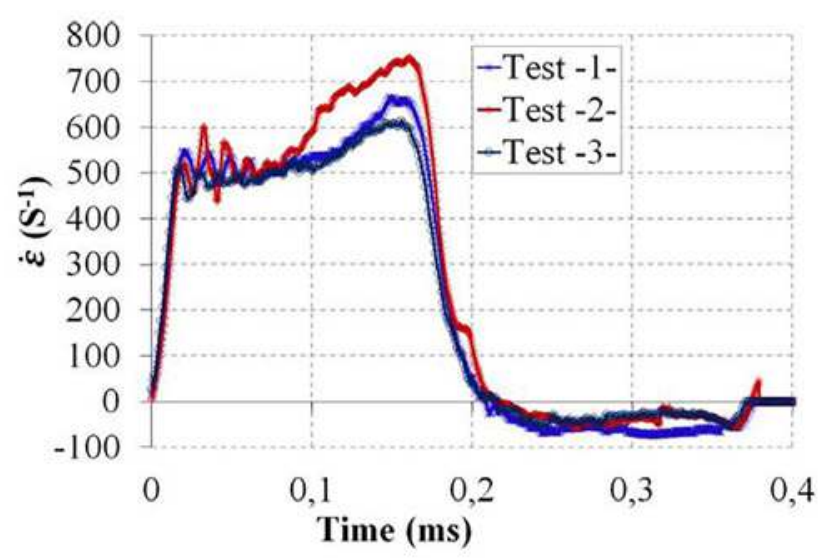

(c) 3 bar

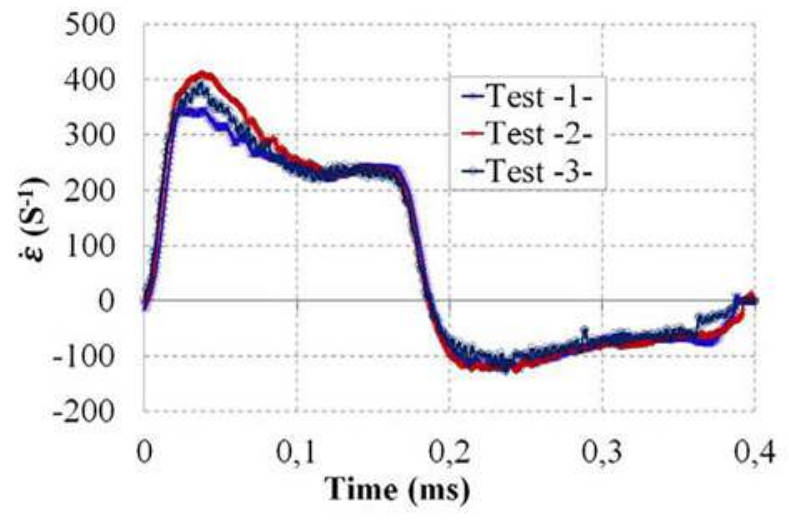

(b) 2 bar

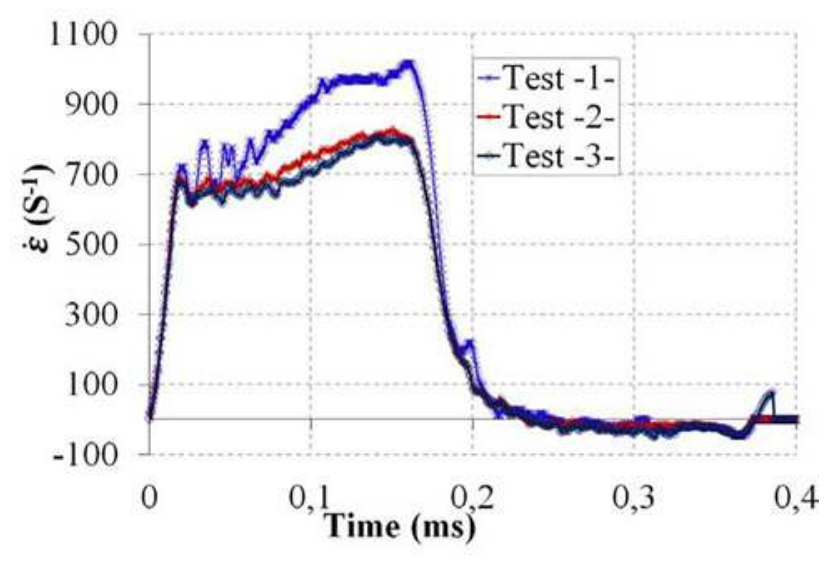

(d) 4 bar

Fig. 4. Test reproductibility of strain rate evolution vs. time for impact pressure.

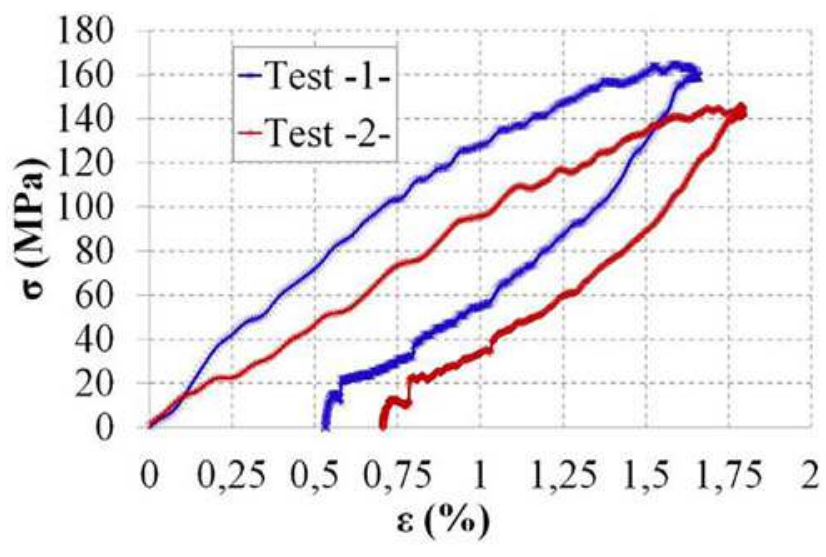

(a) $P=1$ bar $\left(210 \mathrm{~s}^{-1}\right)$

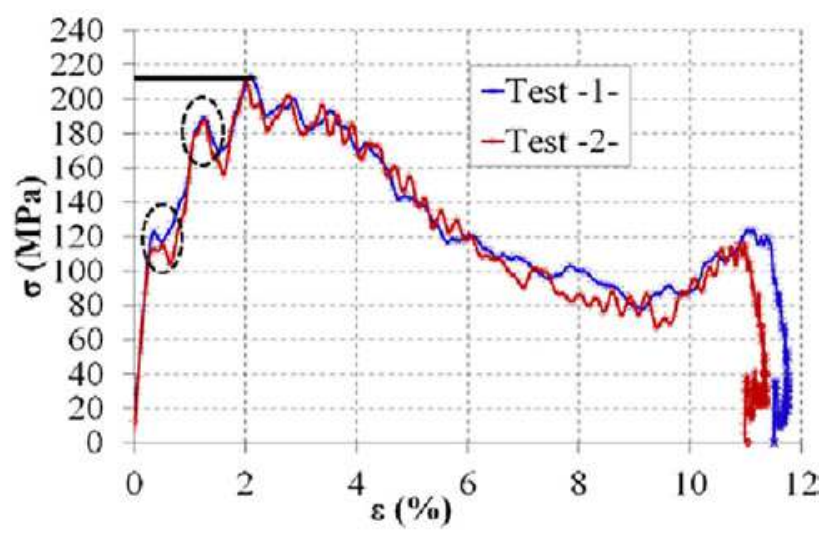

(b) $P=4$ bar $\left(712 s^{-1}\right)$

Fig. 5. Test reproducibility for IP tests.

previous works [3-12]. As the case of strain rate, one can see that the incident load and velocity profiles reveal clearly the appearance of a second peak which characterizes the presence of macroscopic damage for the damaged tests, as previously mentioned. Here, it should be pointed out that not only the strain rate but also the incident load and velocity responses are sensitive in detecting damage in the composite specimen under dynamic solicitation.

Fig. 7 shows the stress vs strain and the time variations curves of the assembled specimen during dynamic compression tests over strain rates: $210,312,528$ and $713 \mathrm{~s}^{-1}$. The results have shown that strain rate has a significant effect of the dynamic responses (stress vs strain, strain rate vs time, load vs time and velocity vs time) of the assembled specimen. It can be noticed from the graph of stress vs strain (Fig. 7a) that sample stiffness increases with increase in strain rate from 210 to $713 \mathrm{~s}^{-1}[3-12,27,28]$ and increase in maximum stresses are associated with deformation at higher strain rates, except for the case at the strain rate of $312 \mathrm{~s}^{-1}$. All the stress vs strain tendencies show that the initial behavior at low strain is linear and nearly the same. From the strain rate 

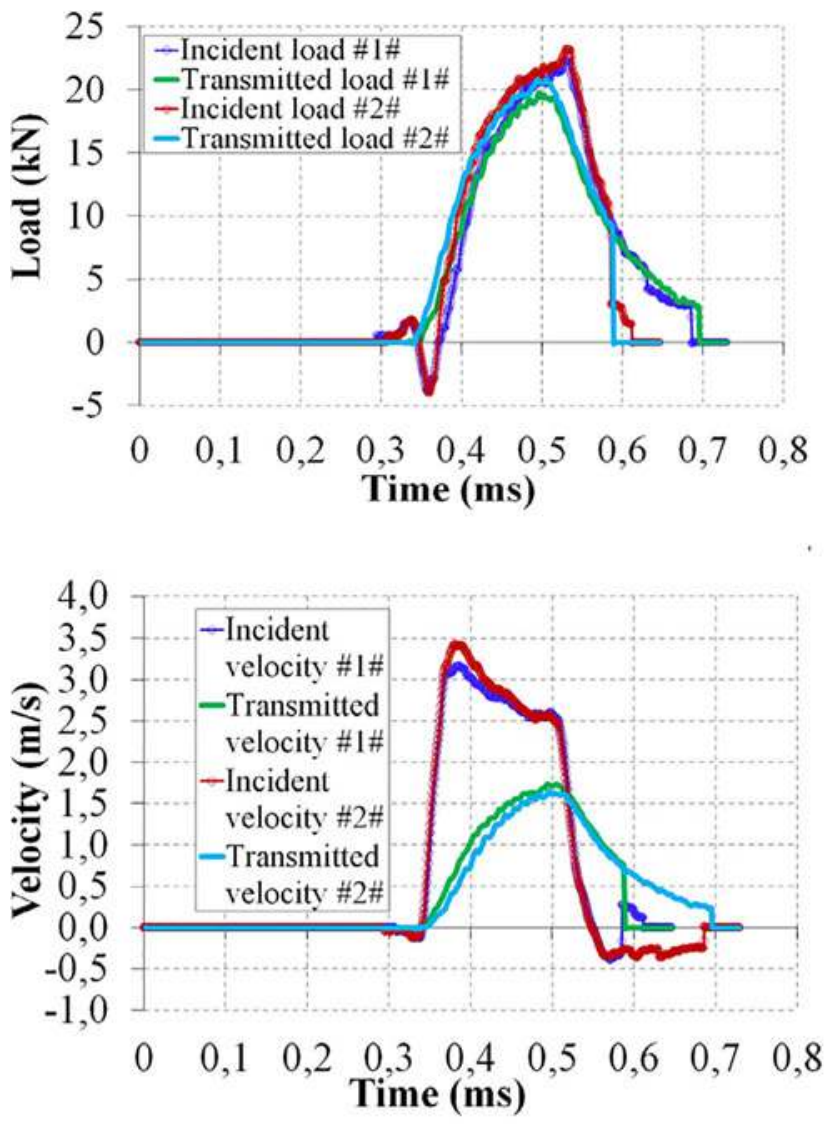

(a) Non damaging test, $210 \mathrm{~s}^{-1}$
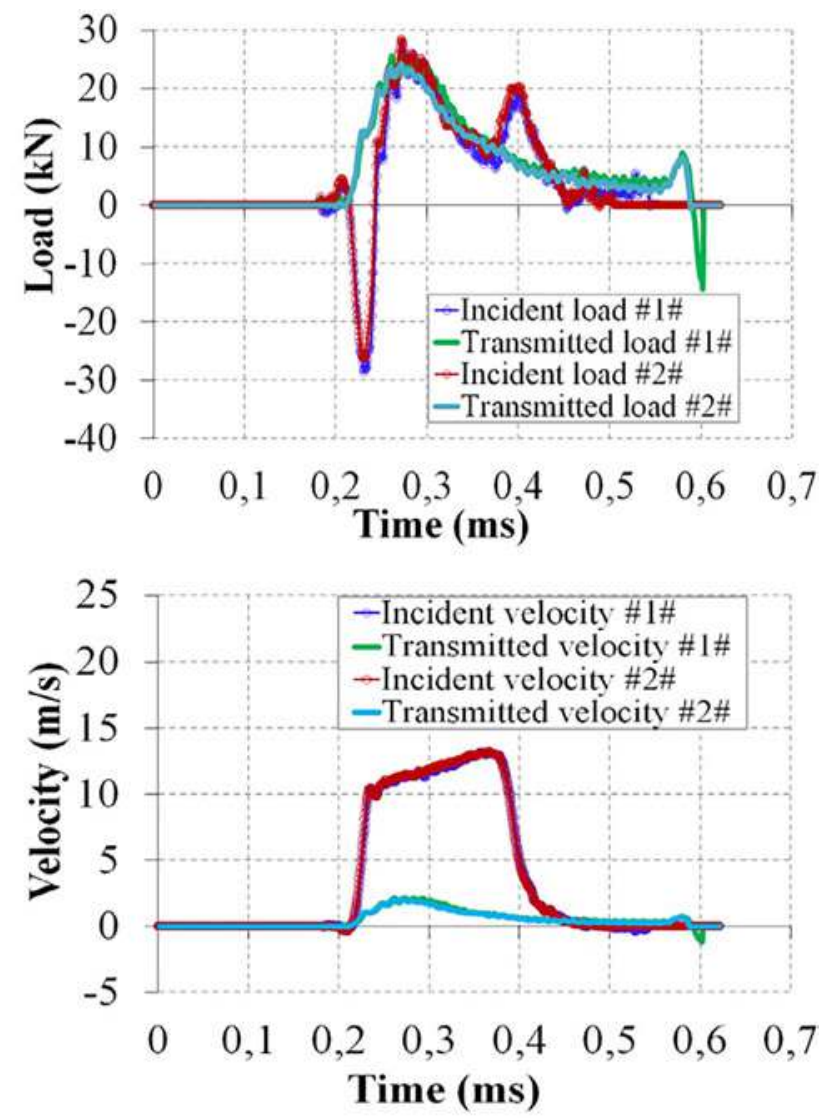

(b) Damaging test, $712 \mathrm{~s}^{-1}$

Fig. 6. Test reproducibility for IP tests, Incident and transmitted loads and velocities.

of $312 \mathrm{~s}^{-1}$, the stress-strain curves present different nonlinear behavior at high strain rate which is associated to different damaging modes and is mainly because of the viscoelastic nature of the polymeric matrix under dynamic compressive load at high strain rate [18].

Fig. $7 \mathrm{~b}$ gives the evolution of the strain rate vs. time of the bonded composite joints for 4 impact pressure. The presence of a second peak is the principal characteristic of these curves and it becomes more apparent with the increase in the impact pressure reflecting the accumulation of damage modes in the sample under dynamic compressive tests. The critical pressure responsible for the appearance of a second peak is around 2 bar (corresponding to $312 \mathrm{~s}^{-1}$ ) for the material used in the test.

Fig. $7 \mathrm{c}-\mathrm{f}$ show that the incident and transmitted load and velocity durations decrease with the increase in the strain rate under the dynamic compressive tests except for the strain rate of $312 \mathrm{~s}^{-1}$ case. This can be explained as following: at lower strain rates, the material has much time to respond and to resist the damage accumulation process. This can be explained by the laminate splitting along almost each ply for the assembled samples tested at the strain rate of $312 \mathrm{~s}^{-1}$, as shown in Fig. 8a. However, at the highest strain rate of $713 \mathrm{~s}^{-1}$, the laminate has little time to respond and this is traduced by the formation of one major part of laminate, which is about half of the initial thickness and the rest of the laminate splitting into many sublaminates, as shown in Fig. 8 b. We will see in detail the damage modes of the assembled specimens during the dynamic compression tests in Section 3.2

In case of the strain rate vs time, the second peaks of the incident load and velocity vs time curves increase with the increase in the strain rate, as shown in Fig. $7 \mathrm{c}$ and e. This result reinforces that the strain rate behavior and the incident dynamic response (load and velocity) of the bonded composite joints are critical in detecting damage under dynamic compressive loading.

To our knowledge, no studies propose constitutive empirical models traducing the effect of the strain rate on the dynamic parameters of bonded composites joints because of the scarcity of reliable experimental data, especially for dynamic testing. However, the strain rate effect on the damage parameters for metals [29] and composites [30-33] have recently proposed with an objective of modeling the dynamic behavior of material subjected to impact tests.

In this study, we will propose empirical laws describing the dependency of the dynamic parameters of the bonded composite joints on the impact pressure and on the strain rate subjected to in-plane dynamic compression test will be proposed. To simplify the graphic representations, the applied strain rate will be given with respect to the impact pressure. However, the dynamic parameters as the young's modulus $(E)$, the maximum of stress $\left(\sigma_{\max }\right)$, the second peak of the strain rate $\left(\mathrm{P}_{1}\right)$ and the second peak of the incident velocity $\left(\mathrm{P}_{2}\right)$ will be represented as a function of the strain rate. Fig. 9 shows the obtained trends of dependencies of strain rate, $\mathrm{E}, \sigma_{\max }, \mathrm{P}_{1}$ and $\mathrm{P}_{2}$ on impact pressure and strain rate. The evolution of the strain rate is approximated by logarithmic equation. This evolution shows two phases: a first phase ( 1 bar $\leq$ Pressure $\leq 2$ bar) where the increase is fast and the second phase where the rise is less marked. Figures show that $\mathrm{E}, \sigma_{\max }, \mathrm{P}_{1}$ and $\mathrm{P}_{2}$ increase with the increase in strain rate. It can be seen that the material stiffness $E$ is sensitive to strain rate, as shown in Fig. 9b. To accurately describe the experimentally observed dependency of the young's modulus, E, on strain rate, an exponential expression is adopted, as [30]. Similar to [34,35], non-linear equations were found to accurately describe the strain-rate effects on the maximum stress $\sigma_{\max }$ and the two second peaks $\left(\mathrm{P}_{1}, \mathrm{P}_{2}\right)$ of the bonded composite joints under dynamic compressive loading. 


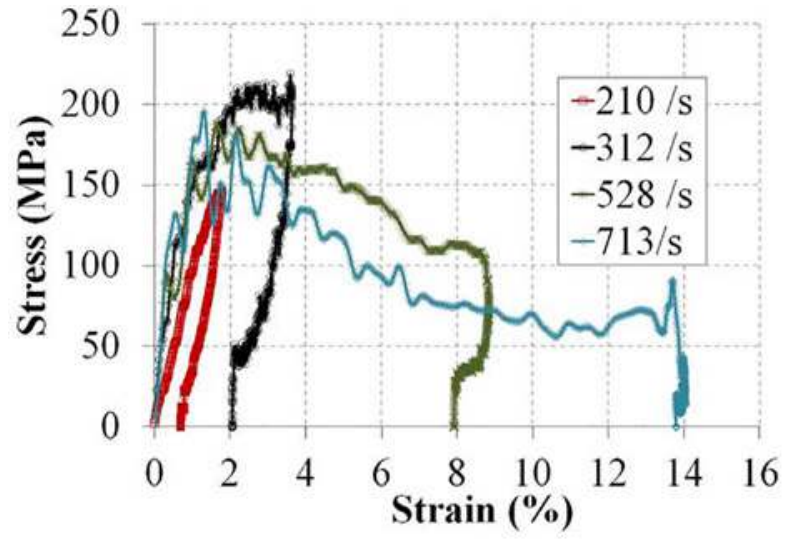

(a)

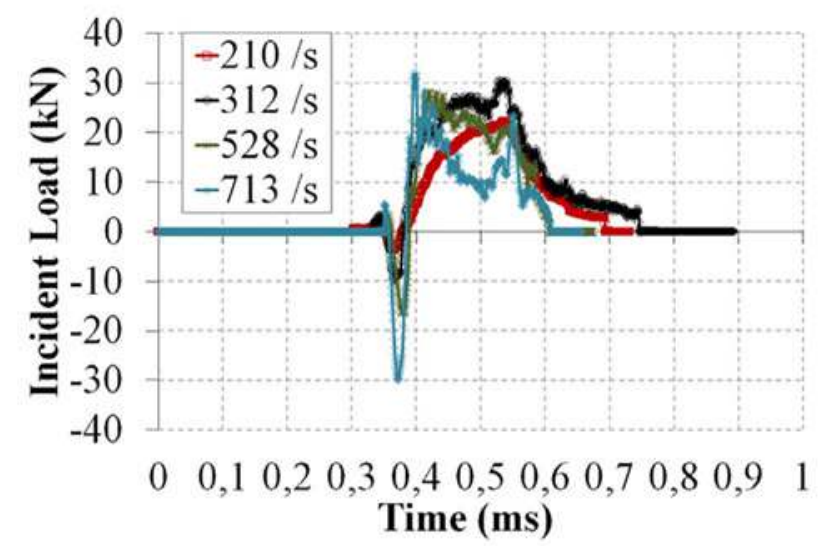

(c)

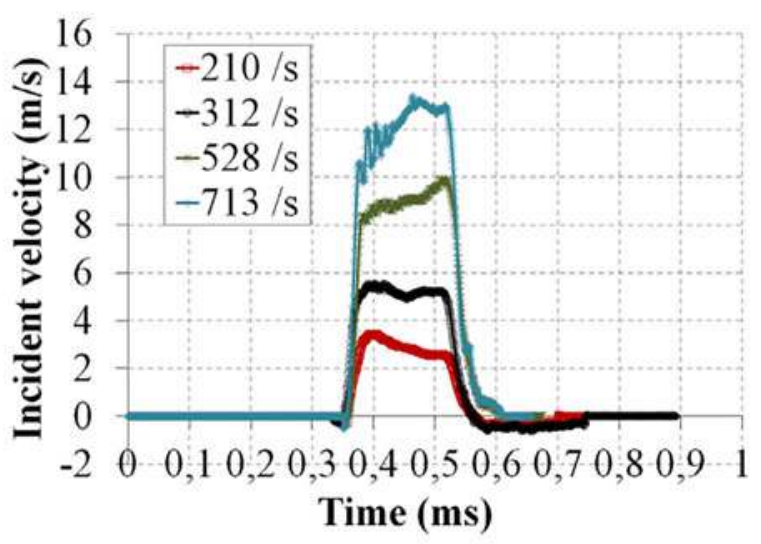

(e)

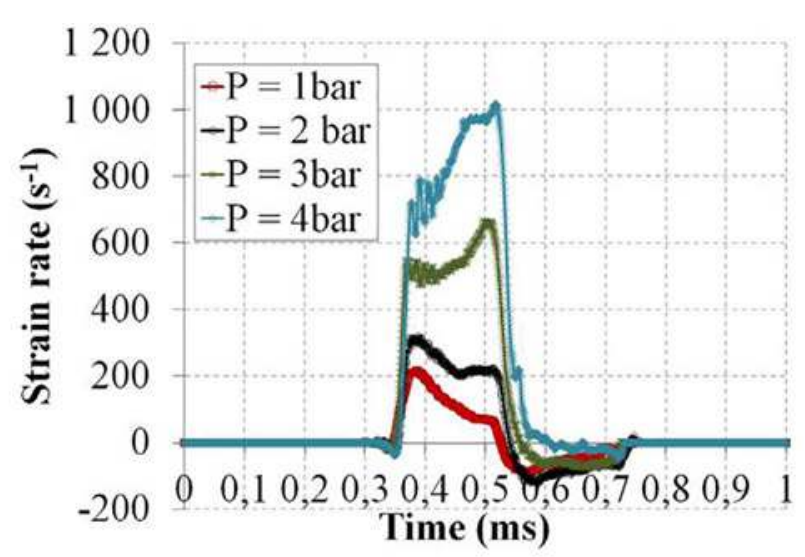

(b)

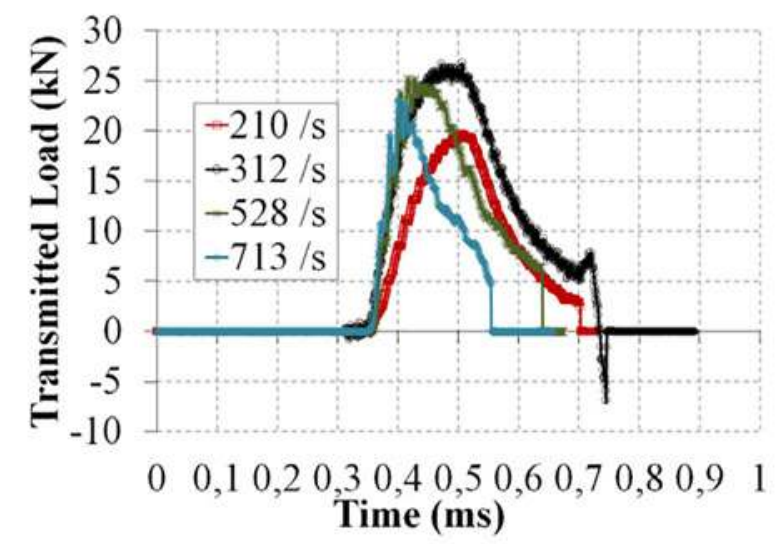

(d)

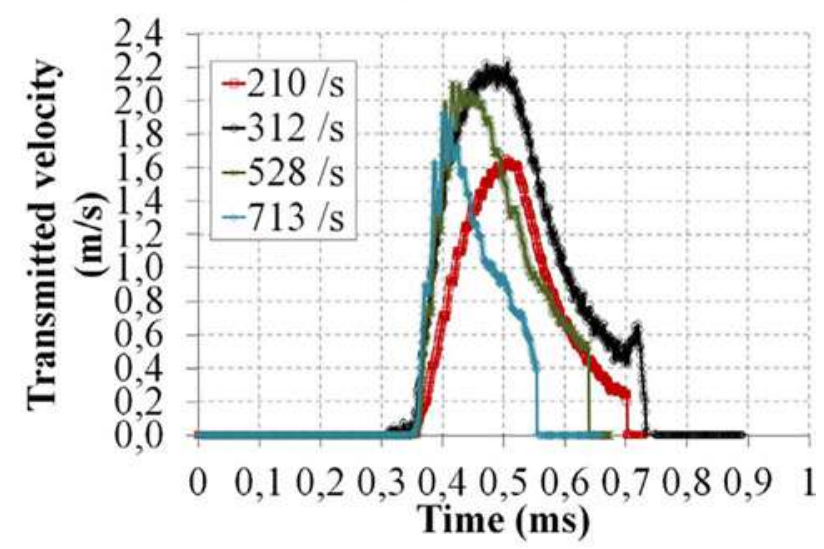

(f)

Fig. 7. Dynamic parameters for different impact pressures.

It is interesting to note that these non-linear equations were generated from the empirical curves (Fig. 9a-d) of dynamic parameters versus strain rate under dynamic compression. They are similar to the obtained quadratic equations describing the evolutions of the dynamic behavior of glass/epoxy composite during dynamic compression $[31,32]$. Furthermore, in literature, authors used usually the non-linear strain-rate-dependent damage evaluation for dynamic modelling under impact [30]. But, in this study, it was found that nonlinear formulations of dynamic parameters are also necessary to describe the mechanical response of adhesively bonded joints under compressive loading. It is obvious that the introduction of the inertial effect may affect this behavior. Thus, these exponential forms should be altered significantly taking into account the effect of the inertia behavior.

Based on these empirical trends, nonlinear strain-rate-dependent evolutive constitutive empirical models of dynamic parameters were adopted to describe the dynamic response and damage of the bonded composite joints under in-plane dynamic compressive loading.

Eqs. (1)(4) show the evolution of the various parameters of the dynamic compression of adhesively-bonded composite joints under different strain rates.

$E=6486.5 . \exp (0.0026 . \dot{\varepsilon}) ; \mathrm{R}^{2}=0.9$

$\sigma_{\max }=34.405 . \dot{\varepsilon}^{0.26} ; \mathrm{R}^{2}=0.91$ 

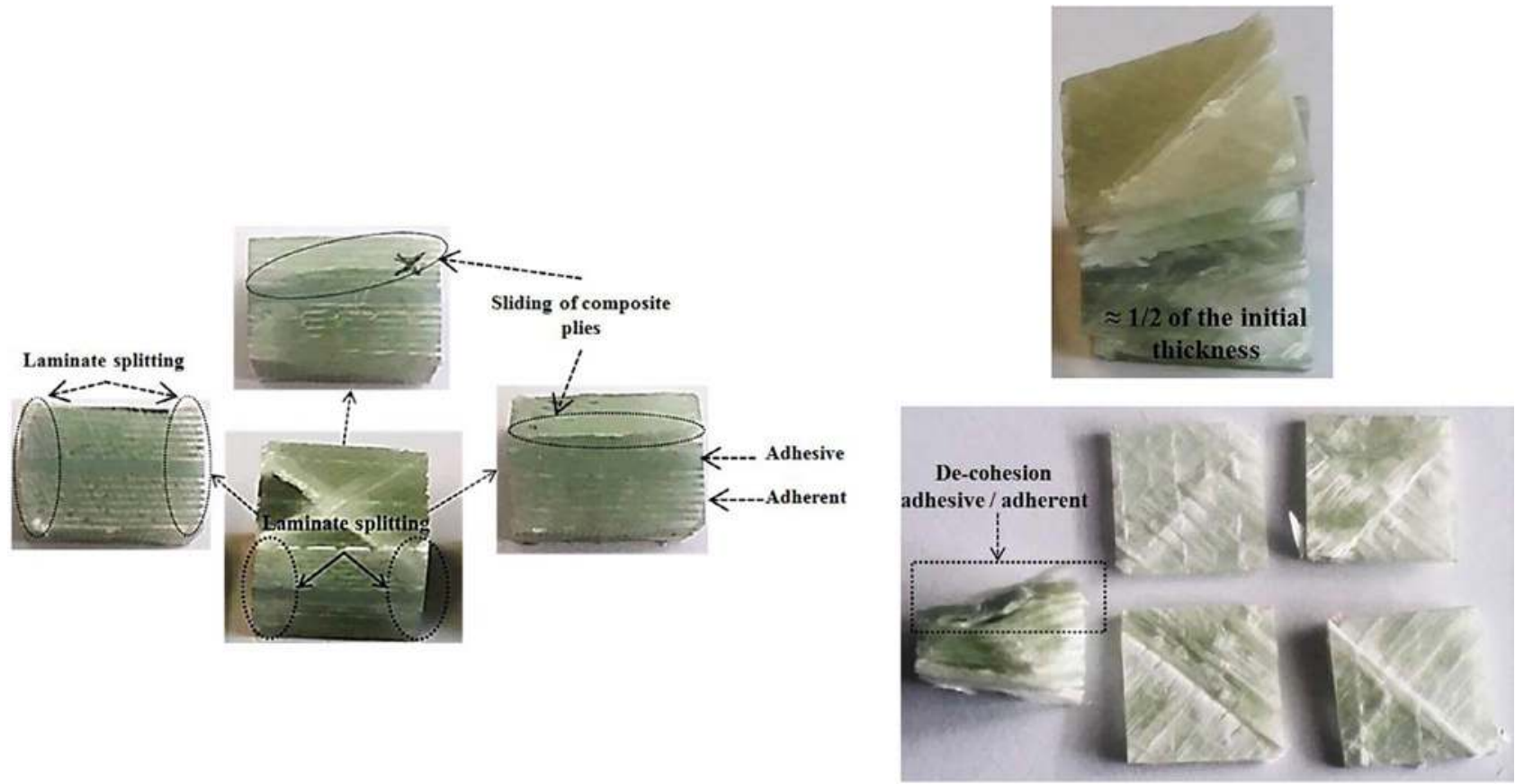

(a)

(b)

Fig. 8. Cross-sectional views of specimens tested at (a) $312 \mathrm{~s}^{-1}$ and at (b) $713 \mathrm{~s}^{-1}$

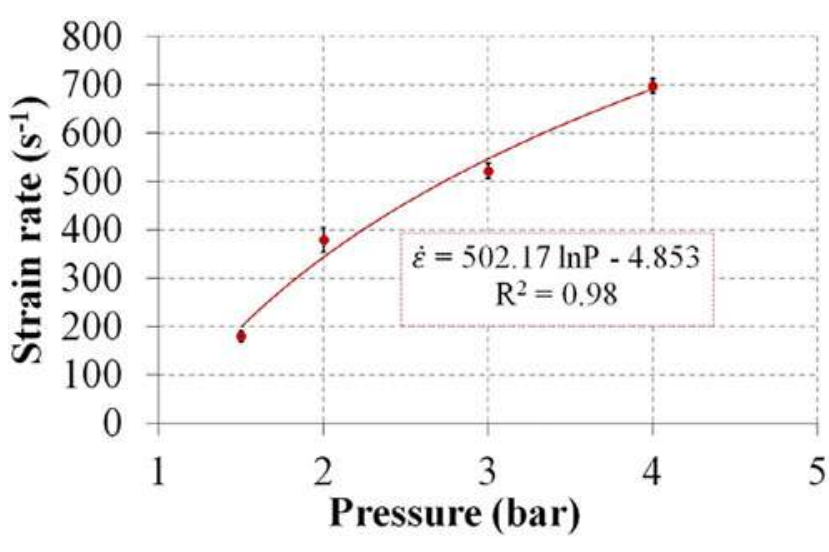

(a)

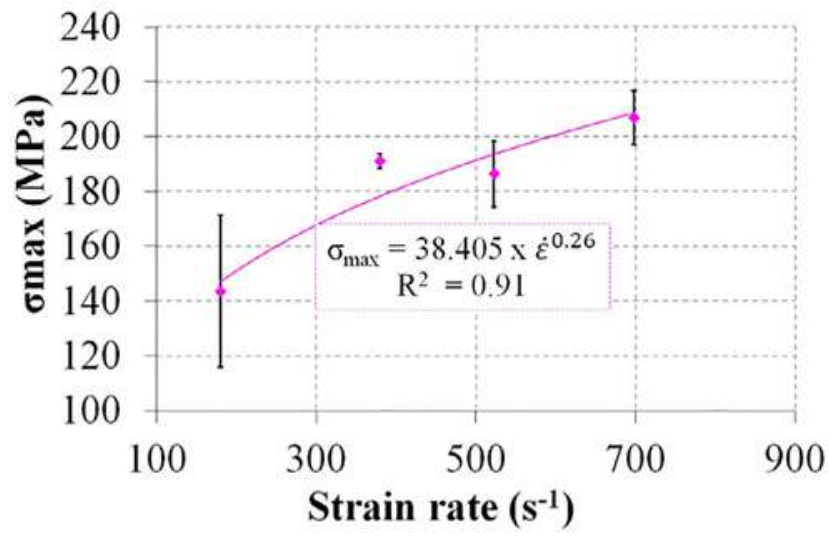

(c)

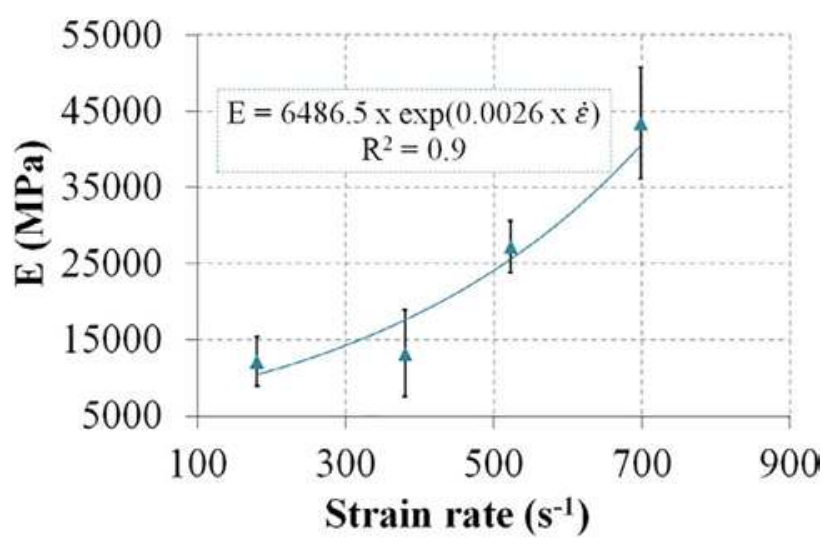

(b)

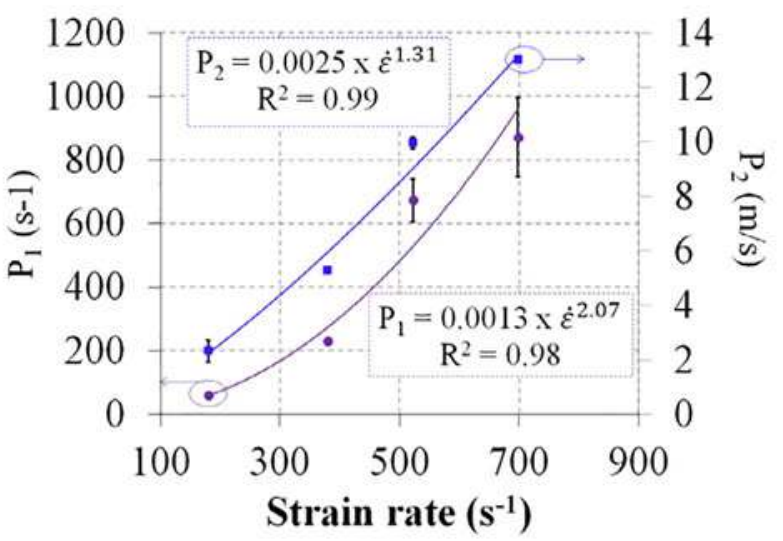

(d)

Fig. 9. Strain rate vs pressure, E, $\sigma_{\max }, \mathrm{P} 1$ and $\mathrm{P} 2$ vs strain rate evolutions. 


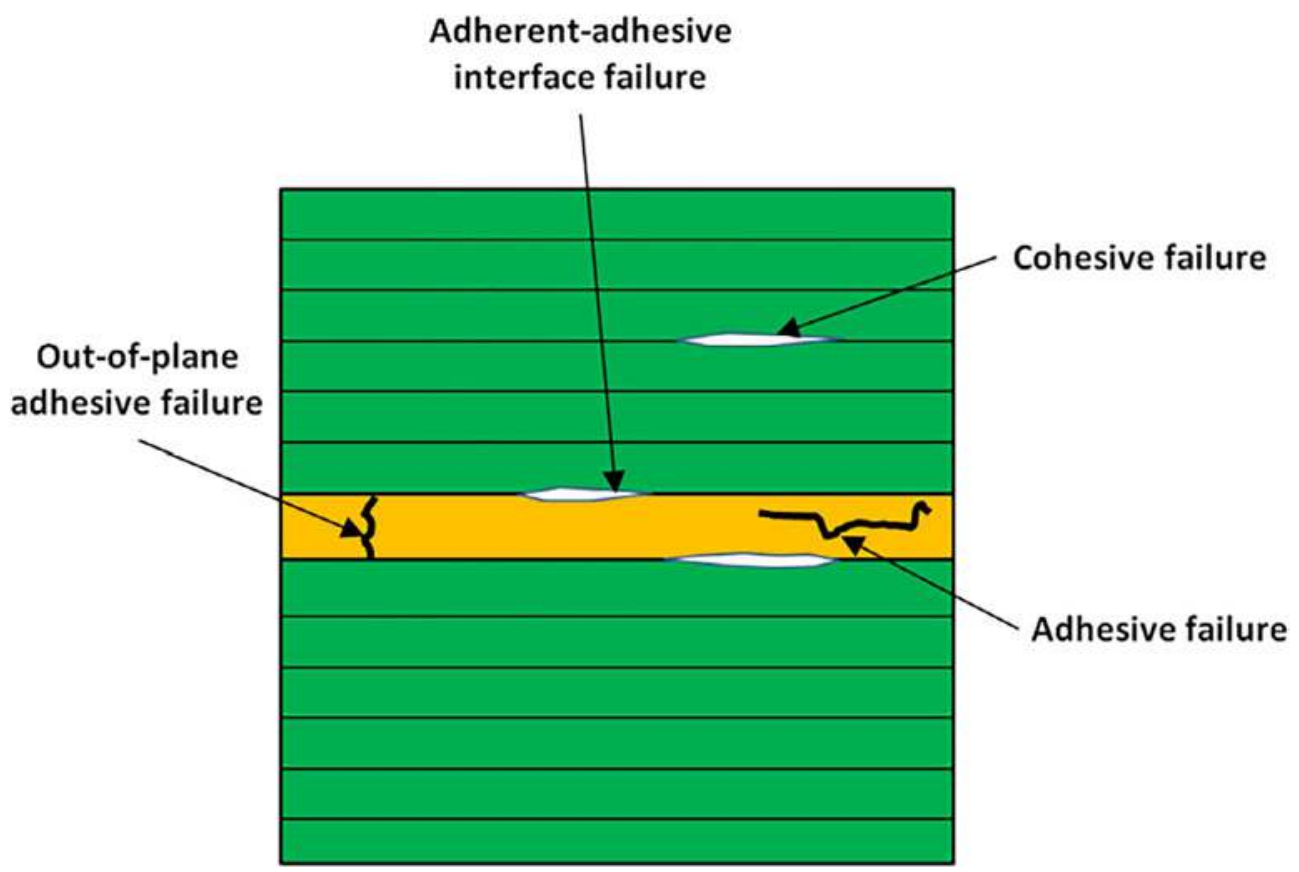

Fig. 10. Typical failure modes of an adhesively bonded composite joint.

$P_{1}=0.0013 . \dot{\varepsilon}^{2.07} ; \mathrm{R}^{2}=0.98$

$P_{2}=0.0025 \cdot \dot{\varepsilon}^{1.31} ; \mathrm{R}^{2}=0.99$

\subsection{Macroscopic damage mechanisms}

Several studies demonstrate that the failure of an adhesively bonded joint is caused by the following modes (Fig. 10): (i) failure of the adherend due to compression, (ii) adherend-adhesive interface failure, (iii) cohesive failure (entirely within the adhesive), and (iv) out-ofplane adherend failure [36]. No studies are found in the literature that propose an accurate experimental procedure to analyse the adhesively bonded joint damage modes during dynamic compression tests.

In this section, the damage history in the assembled specimens until final failure during the in-plane dynamic compression tests will be discussed. Fig. 11 demonstrates the evolution of macroscopic damage as a function of impact pressure from 1 to 4 bar corresponding to $210-713 \mathrm{~s}^{-1}$ strain rates. The damage occurs for an impact pressure higher than 1 bar $\left(\dot{\varepsilon}=210 \mathrm{~s}^{-1}\right)$. The damage is initiated by a crack forming the letter $\mathrm{X}$ according to the diagonal of the external layers. The evolution of this crack generates substantial displacement in the thickness direction and creates a crack forming the letter V. This V shape crack initiates from the interface incident or transmitted bar/ specimen and then converges towards the adhesive interlayer because of its weakest link in the bonded composite specimens. This involves delamination as well fiber fracture, the failure of the adhesive interlayer and the final abrupt rupture caused by the laminate splitting at high strain rate.

To follow in details the history of defect development in the assembled samples until final failure, a real time monitoring of the damage scenario is necessary. High-speed camera with interframe time $0.02 \mathrm{~ms}$ was used to visually observe how damage occurred and propagated in the specimen during dynamic compression tests. Fig. 12 shows high-speed photographs of a test conducted at the highest strain rate of $713 \mathrm{~s}^{-1}$ and shows clear experimental evidence of the damage progression during impact. It can be noted that the adhesively bonded joints failed catastrophically. The first evidence of damage appeared after $0.4 \mathrm{~ms}(\varepsilon=0.48 \%)$ and manifested by the whitening of material that occurred close to the specimen/transmitted bar interface. This damage occurs because the joint is locally subjected to strains greater than the ultimate material strain. At first stage "small strains" (from $0.4 \mathrm{~ms}(\varepsilon=0.48 \%)$ to $0.8 \mathrm{~ms}(\varepsilon=1.3 \%))$, it can be seen that the damage is developed in priority in the adherents and consisted of matrix cracking, fibre/matrix interface failure and fibre splitting which

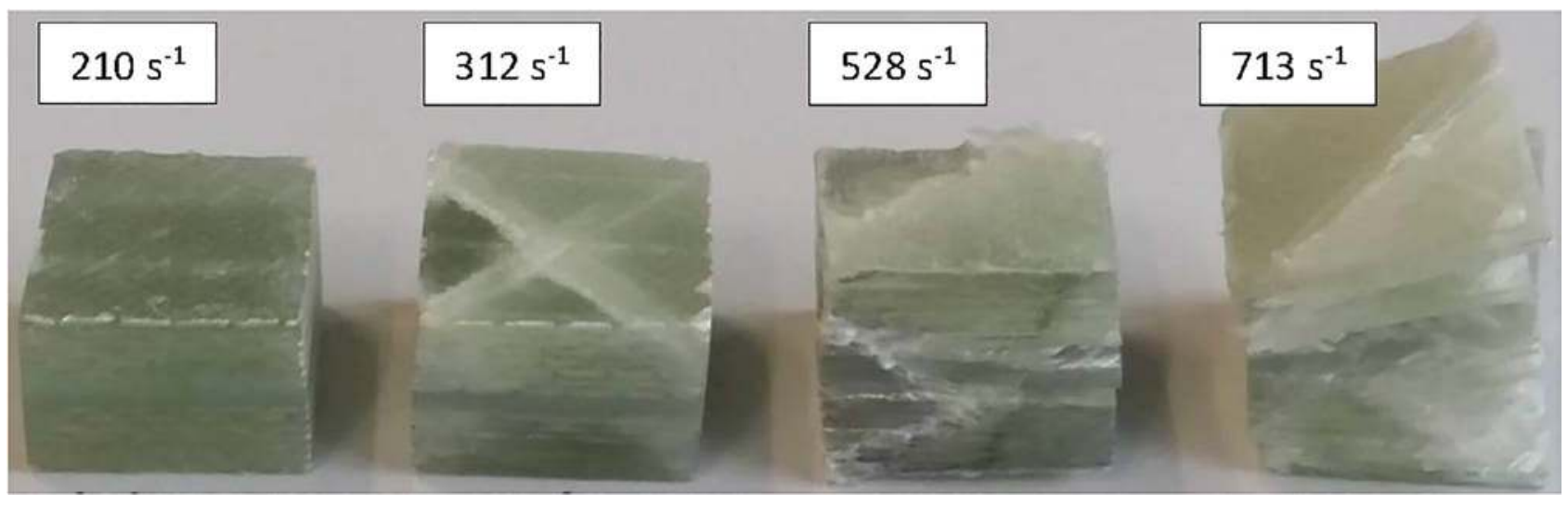

Fig. 11. Recovered specimens after IP dynamic compression tests. 

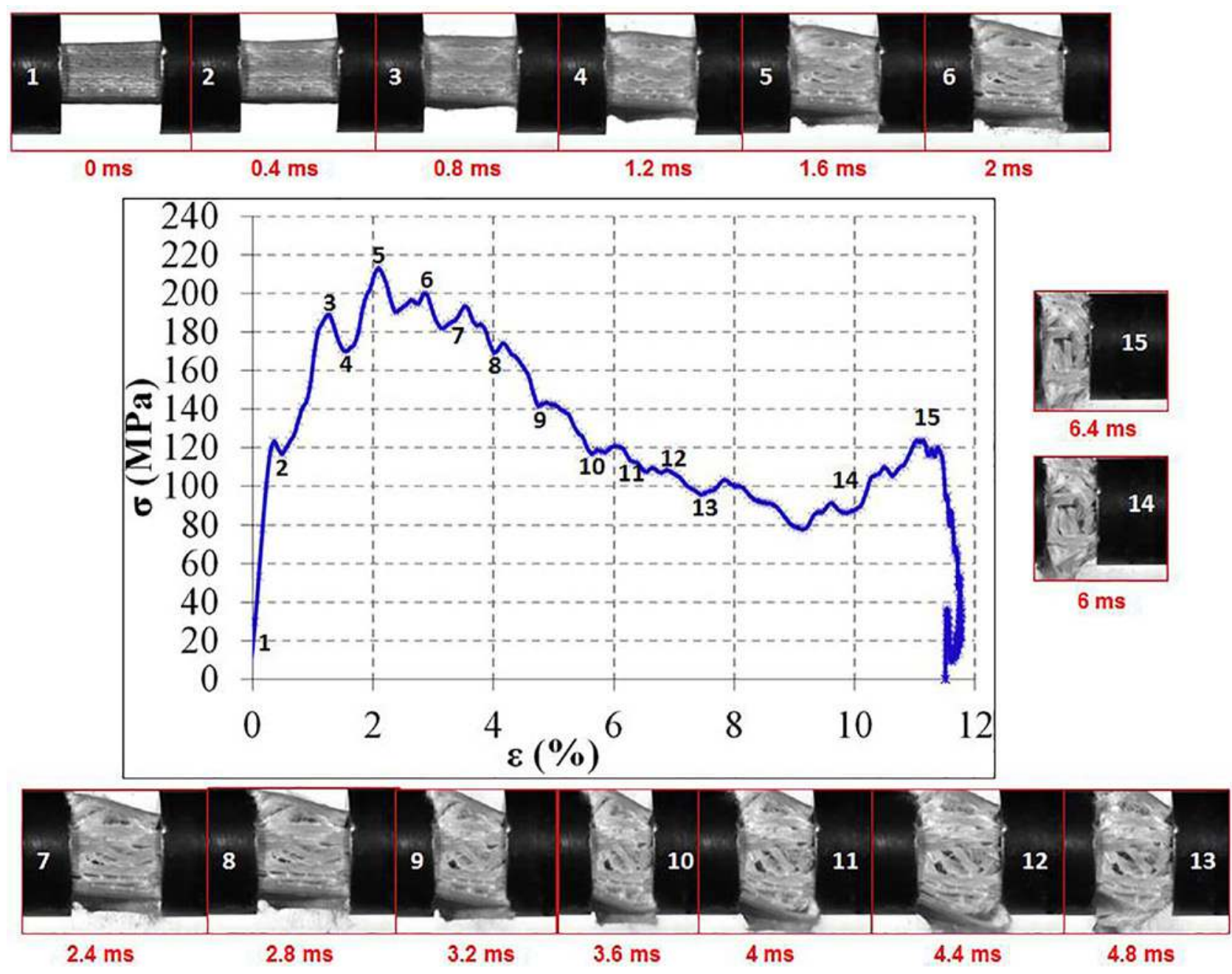

Fig. 12. High speed photograph of real-time dynamic compression test of adhesively bonded joints impacted at high strain rate of $713 \mathrm{~s}^{-1}$.

manifested by the appearance of white zones in adherents. Under medium strain (at $0.8 \mathrm{~ms}(\varepsilon=1.3 \%)$ ), the white zones increase in size and converge towards the two ends of the joint.

As the failure dynamic load is reached at $1.2 \mathrm{~ms}(\varepsilon=1.55 \%)$ (according to Fig. 4) the damage focuses in either the composite adherent and the adhesive when the individual components of damage coalisce and form a V shape and delamination on its tip that involves a buckling of the external layers. Once delamination is formed, continues to grow with strain (from $1.2 \mathrm{~ms}(\varepsilon=1.55 \%)$ to $4.4 \mathrm{~ms}(\varepsilon=7 \%)$ ) leading to instant joint failure but the deformation of the adhesive layer is because of its viscoelastic behavior under dynamic loading [37,38]. At the end of dynamic compression (at $4.8 \mathrm{~ms}(\varepsilon=7.8 \%$ ) for example), it is clearly observed that the buckling of the external layer involves a separation of several layer blocks and the appearance of all the failure modes of the adhesively bonded joint as presented in Fig. 10: failure of the adherend due to compression, (ii) adherend-adhesive interface failure, (iii) cohesive failure (entirely within the adhesive), and (iv) out-of-plane adherend failure. It can also be seen that matrix is turned into powder from coalescence of matrix micro-cracks during the dynamic compression test. Based on the above experimental results and observations, it can be concluded that the viscoelasticity of the adhesive layer has an important role in the failure mechanisms of joints under dynamic loading. Therefore, is vital to take in the account the effect of the viscoelastic behavior (of matrix and adhesive) and the strain rates effects in the modeling of the dynamic behavior of joints for design and safety purposes.

When the recovered specimens were examined by touching after the test, it is believed that there is a significant heat dissipation by the damage modes during impact.

In the case of a composite material or adhesively bonded composite joints, the heat dissipation may be caused by either matrix and adhesive plasticity or occurrence and accumulation of damage modes under dynamic solicitation. With this in mind, Palmese et al. [39] showed that the glass transition temperature of the interphase region surrounding a fiber of a polymeric matrix composite is much lower that that of the bulk matrix material. Thus, increase in temperature even in small degree Celsius during the damage in fiber reinforced matrix, may have dramatic effects on the structural integrity of these composites. Thus, it is important to take into account the effect of the strain rate on the dynamic properties, damage process and on the heat generation when designing a bonded joint under dynamic loading.

Now a day, most of the work on the composite materials has been focused to demonstrate the existence of internal heating mechanisms of fiber reinforced ceramic composite under various loading conditions. Holmes and Cho [40] showed that there is significant frictional heating at the fiber-matrix interface under cyclic loading. Furthermore, Lankfor et al. [41] observed localized matrix melting in fiber reinforced ceramic under dynamic tension loads especially at high strain rates. The study of Li et al. [42] focused on the investigation of the heat dissipation in fiber reinforced polymeric matrix material under compression and tension dynamic tests through in plane and out-of plane directions using the SHPB technique. An infrared detector array was used to monitor the changes in temperature during dynamic tests in situ and in real time. These authors supposed that the heat generation under dynamic tests 


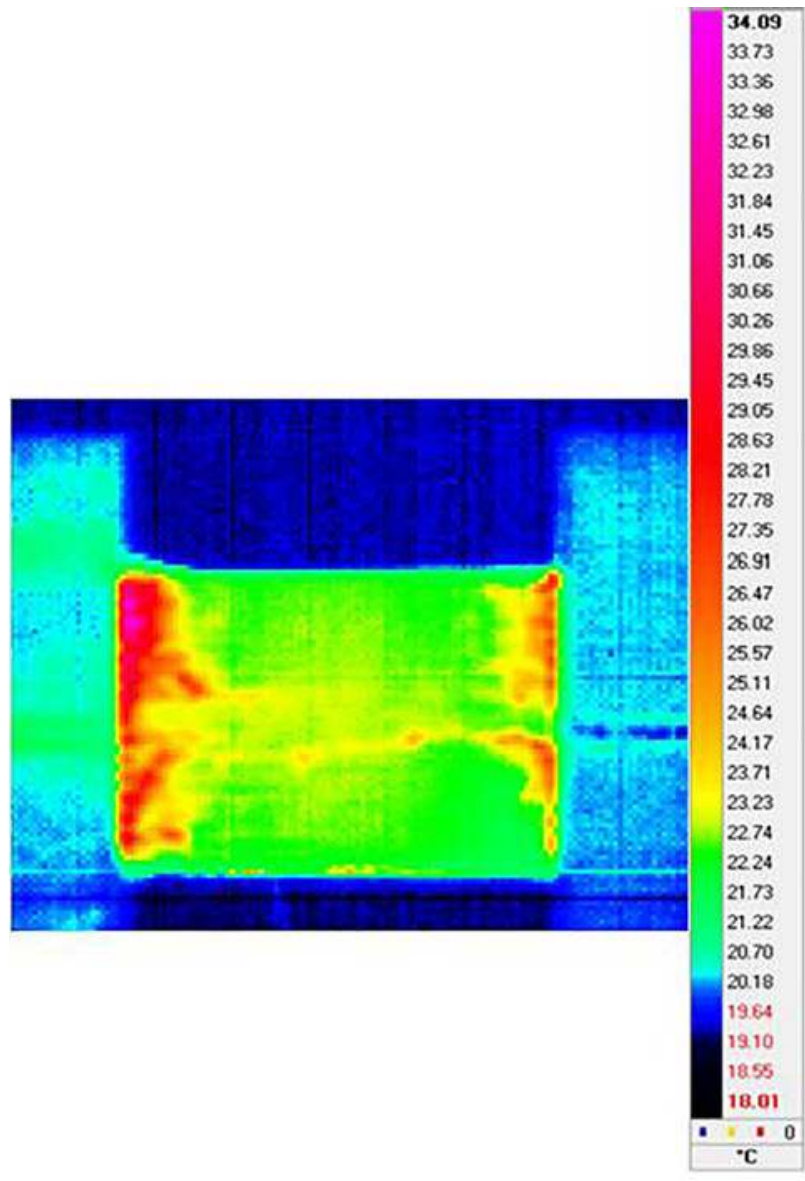

(a) $\dot{\varepsilon}=312 \mathrm{~s}^{-1}$

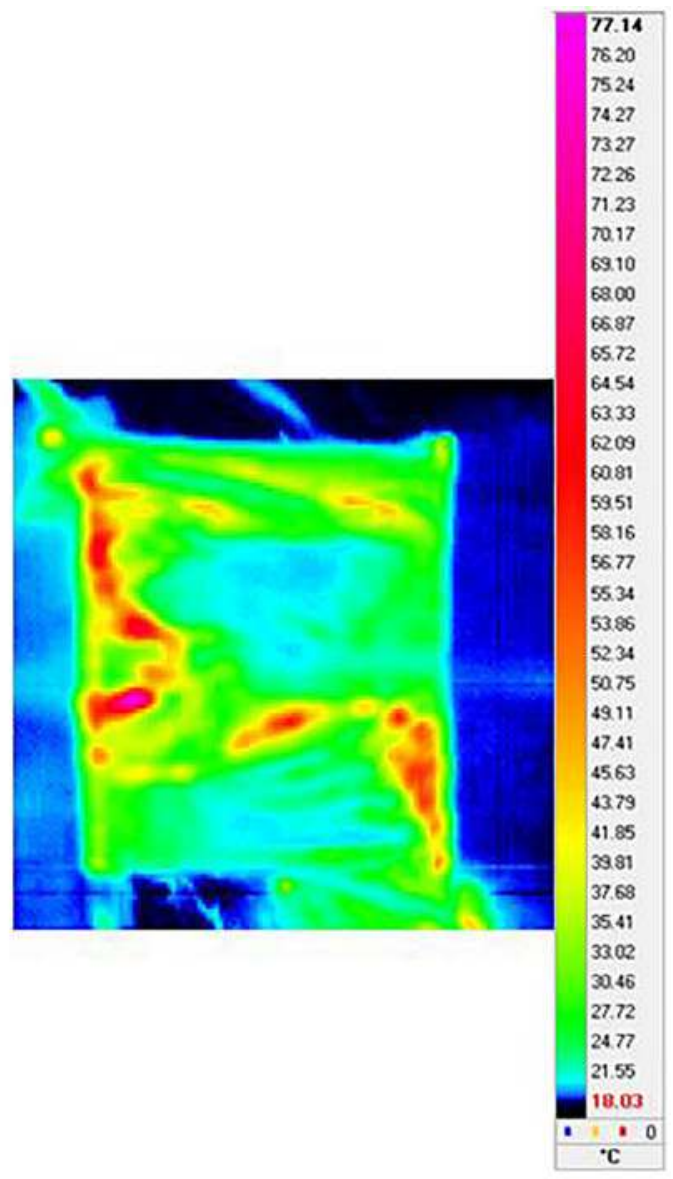

(b) $\dot{\varepsilon}=713 s^{-1}$

Fig. 13. Heating of the sample during damage.

may be a consequence of matrix plastic work and/or damage accumulation. The goal of their study is to quantify the amount heat dissipation during both dynamic tests at high strain rates and to identify the mechanisms that lead to this dissipation. To do this, both dynamic tests and temperature measurements were carried out on fiber reinforced matrix composite and non-reinforced matrix specimens. Their results proved that the temperature rise in the case of the fiber composite is because of damage only and there is no temperature rise in the case of the non-reinforced matrix specimens. Furthermore, they observed that the temperature increase during compression and tension tests through the three anisotropic directions of the composite material is different and this can be explained only by the difference of damage modes in each direction. Tarfaoui et al. [43] detected the heat dissipation in E-glass/Epoxy laminated composites under dynamic compression at high strain rate from 200 to $2000 \mathrm{~s}^{-1}$ using SHPB and an infrared camera. Their study showed that the damage through specimens differs and the temperature change depending on the damage mode and their maximum exceed $219^{\circ} \mathrm{C}$. These authors concluded that the mechanical impact energy, dissipated as heat is spent in the formation of different damage modes as matrix cracks, delamination, and rupture of fibers during the dynamic compression tests.

Fig. 13 shows the rise of heat dissipation in our impacted adhesively bonded joints under dynamic compression tests at 312 and $713 \mathrm{~s}^{-1}$ using an infrared camera, as the same case of Tarfaoui et al. [43]. It is clearly seen that the temperature increase in dynamic tests depends on the strain rate $\left(34.09^{\circ} \mathrm{C}\right.$ at $312 \mathrm{~s}^{-1}$ against $77.14^{\circ} \mathrm{C}$ at $\left.713 \mathrm{~s}^{-1}\right)$ and the load direction. This increase is due to the multiplication of matrix cracks and damage mode, as demonstrated by Tarfaoui et al. [43]. The temperature measurement needs to be improved in order to obtain realtime infrared images using the infrared technique. However, the first results show that for IP tests, the temperature increment exceeds $30^{\circ} \mathrm{C}$ with initial temperature around $20^{\circ} \mathrm{C}$.

Therefore, a real time and an investigation of the heat generated during impact may make an important contribution to the damage mechanism. This issue will be discussed in the next paper.

\section{Conclusion}

In the course of this study, an experimental approach was implemented with an aim of investigating the in-plane dynamic mechanical behavior of an adhesively bonded composite joints. Samples were tested at four different impact pressures of 1, 2, 3, 4 bar and strain rates of $210,312,528,713 \mathrm{~s}^{-1}$ respectively with SHPB apparatus. It has been concluded that materials have shown a strength dependency on strain rate and there is considerable increase in dynamic parameters with the increase in the strain rate. Based on experimental results, empirical laws have been formulated linking the dynamic properties of the adhesively bonded joints with the strain rate. The compressive failure modes for in in-plane loading of specimens were successfully observed in real time compression tests using high-speed photography camera at a farming rate of 50,000 images per second. As the strain rate increases more damage modes can be seen i.e. matrix cracks, delamination and failure of adhesive interlayer. Specimens fail due to laminate splitting at low strain rates, with delamination and adhesive/adherent interfacial separation dominating the high strain rate failure mode. As a future study, it is recommended to examined and quantify the heat 
dissipation generated by damage modes using dynamic compression tests under a wide range of strain rates. This will enable us to develop constitutive models of dynamic response, which take into account the effect of strain rate, viscoelastic nature of the polymeric matrix \& adhesive interlayer and the heat generated by damage mechanisms.

\section{Acknowledgments}

This work was funded by DGA (Direction générale de l'armement Ministry of Defense, France), MRIS project: Study of the thermomechanical behavior of composites under dynamic loading. The Authors of this paper gratefully acknowledge the financial support of the DGA, France. Acknowledgments have also addressed to Pr. Bruno Mortaigne from DGA.

\section{References}

[1] Hou JP, Ruiz C. Measurement of the properties of woven CFRP T300/914 at different strain rates. Compos Sci Technol 2000;60(15):2829-34.

[2] Gilat A, Golberg RK, Roberts GD. Experimental study of strain rate dependent behavior of carbon/epoxy composite. Compos Sci Technol 2002;62:1469-76.

[3] Tarfaoui M, Choukri S, Neme A, Mliha-Touati M. Thermo-mechanical state of bimaterial with an interface crack, chapter. Fract Nano Eng Mater Struct 2006:329-30.

[4] Tarfaoui M, Choukri S, Neme A. Effect of fibre orientation on mechanical properties of the laminated polymer composites subjected to out-of-plane high strain rate compressive loadings. Compos Sci Technol 2008;68(2):477-85.

[5] Tarfaoui M, Choukri S, Neme A. Damage kinetics of glass/epoxy composite materials under dynamic compression. J Compos Mater 2009;43(10):1137-54.

[6] Tarfaoui M, Choukri S, Neme A. Dynamic response of symmetric and asymmetric Eglass/epoxy laminates at high strain rates. Key Eng Mater 2010;446:73-82.

[7] Tarfaoui M. Experimental investigation of dynamic compression and damage kinetics of glass/epoxy laminated composites under high strain rate compression. In Advances in composite materials; 2011. p. 359-82 [Chapter 16].

[8] Gueraiche L, Tarfaoui M, Osmani H, EL Malki Alaoui A. A practical note for SHPB test with new algorithms for delimiting pulses. Compos Struct 2015;126:145-58.

[9] Arbaoui J, Tarfaoui M, EL Malki Alaoui A. Mechanical behavior and damage kinetics of woven E-glass/Vinylester laminate composites under high strain rate dynamic compressive loading: experimental and numerical investigation. Int J Impact Eng 2016:44-54.

[10] Arbaoui J, Tarfaoui M, EL Malki Alaoui A. Dynamical characterisation and damage mechanisms of E-glass/Vinylester woven composites at high strain rates compression. J Compos Mater 2015:1-11.

[11] Arbaoui J, Tarfaoui M, Bouery C, EL Malki Alaoui A. Comparison study of mechanical properties and damage kinetics of 2D and 3D woven composites under high-strain rate dynamic compressive loading. Int J Damage Mech 2016:1-22.

[12] Arbaoui J, Tarfaoui M, Bouery C, EL Malki Alaoui A. Mechanical behavior and damage kinetics of woven E-glass/vinylester laminate composites under high strain rate dynamic compressive loading: Experimental and numerical investigation. Int J Impact Eng 2016;87:44-54.

[13] Kumar P, Garg A, Argawal BD. Dynamic compressive behavior of unidirectional GFRP for various fiber orientations. Mater Lett 1986;4(2):111-6.

[14] El-Habak AMA. Mechanical behavior of woven glass fiber-reinforced composites under impact compression load. Composites 1991;22(2):129-34.

[15] Harding J. Effect of strain rate and specimen geometry on the compressive strength of woven glass-reinforced epoxy laminates. Composites 1993;24(4):323-32.

[16] Sierakowski RL, Nevill GE. Dynamic compressive strength and failure of steel reinforced epoxy composites. J Compos Mater 1971;5:362-77.
[17] Hosur MV, Alexander J, Vaidya UK, Jeslani S, Mayer A. Studies on the o.-axis high strain rate compression loading of satin weave carbon/epoxy composites. Comput Struct 2004; 63: 75-85.

[18] Li Z, Lambros J. Dynamic thermomechanical behavior of fiber reinforced composites. Composites 2000; Part A 31: 537-47.

[19] Carlberger T, Biel A, Stigh U. Influence of temperature and strain rate on cohesive properties of a structural epoxy adhesive. Int J Fract 2009:155-66.

[20] Goglio L. High strain-rate compression and tension behavior of an epoxy bi-component adhesive. Int J Adhes Adhes 2008; 28: 329-39.

[21] Iwamoto T, Toshimasa Nagai, Toshiyuki Sawa. Experimental and computational investigations on strain rate sensitivity and deformation behavior of bulk materials made of epoxy resin structural adhesive. Int J Solids Struct 2010; 47: 175-85.

[22] Martinez MA. Confined compression of elastic adhesives at high rates of strain. Int J Adhes Adhes 1998; 18: 375-83.

[23] Park SJ. Rate-dependent large strain behavior of a structural adhesive. Mech TimeDependent Mater 2003; 7: 143-64.

[24] SharonG, Dodiuk H, Kenig S. Effects of loading rate and temperature on the mechanical properties of structural adhesives containing a carrier. J Adhes 1989; 31: 21 .

[25] Srivastava.V.K. Characterization of adhesive bonded lap joints of C/C-SiC composite and Ti-6Al-4V alloy under varying conditions. International Journal of Adhesion \& Adhesives 2003; 23: 59-67.

[26] D. Bancroft. The velocity of Longitudinal Waves in Cylindrical Bars. Physical Review; 59:588-593. 7.

[27] Ochola RO. Mechanical behavior of glass and carbon fibre reinforced composites at varying strain rates. Compos Struct 2004;63:455-67.

[28] Gilat Amos. Experimental study of strain-rate-dependent behavior of carbon/epoxy composite. Compos Sci Technol 2002;62:1469-76.

[29] Bo Song. Dynamic compressive response and failure behavior of an epoxy syntactic foam. J Compos Mater 2004; 38: 11/.

[30] Song B, Chen W, Weerasooriya T. Quasi-static and dynamic compressive behaviors of a S-2 Glass/SC15 composite. J Compos Mater 2003;37:1723-43.

[31] Randles PW, Nemes JA. A continuum damage model for thick composite materials subjected to high-rate dynamic loading. Mech Mater 1992;13:1-13.

[32] Park SW, Schapery. A viscoelastic constitutive model for particulate composites with growing damage. Int J Solids Struct 1997; 34: 931-947.

[33] Li Y, Ramesh KT, Chin ESC. Viscoplastic deformations and compressive damage in an A359/SiCp metal-matrix composite. Acta Mater 2000;48:1563-73.

[34] Wang L, Yang L. Non-linear viscoelastic constitutive relationship for solid polymers. Adv Impact Dyn 1992:88-116.

[35] Warren TL, Forrestal MJ. Effects of strain hardening and strain-rate sensitivity on the penetration of aluminum targets with spherical-nosed rods. Int J Solids Struct 1998;35:3737-53.

[36] Sheppard Andrew. A damage zone model for the failure analysis of adhesively bonded joints. Int J Adhes Adhes 1998;18:385-400.

[37] Sato C. Dynamic deformation of lap joints and scarf joints under impact loads. Int $\mathrm{J}$ Adhes Adhes 2000;20:17-25.

[38] Iwamoto Takeshi. Experimental and computational investigations on strain rate sensitivity and deformation behavior of bulk materials made of epoxy resin structural adhesive. Int J Solids Struct 2010;47:175-85.

[39] Palmese GR, McCullough RL, Sottos NR. Relationship between interphase composition, material properties and residual thermal stresses in composite materials. J Adhes 1995;52:101-13.

[40] Holmes JW, Cho C. Experimental observations of frictional heating in fiber-reinforced ceramics. J Am Ceram Soc 1992;75:929-38.

[41] Lankford J, Couque H, Nicholls A. Effect of dynamic loadings on tensile strength and failure mechanism in a SiC fibre reinforced ceramic matrix composite. J Mater Sci 1992;27:930-6.

[42] Li Z, Lambros J. Dynamic thermomechanical behavior of fiber reinforced composites. Compos A 2000;31:537-47.

[43] Tarfaoui M, El Moumen A, Ben Yahia H. Damage detection versus heat dissipation in E-glass/Epoxy laminated composites under dynamic compression at high strain rate. Compos Struct 2018;186:50-61. 